\title{
Comparative efficacy and safety of paricalcitol versus vitamin $D$ receptor activators for dialysis patients with secondary hyperparathyroidism: a meta- analysis of randomized controlled trials
}

\author{
Yifeng Xie ${ }^{1 *}$ (D) Peiling Su', Yifan Sun², Hongsheng Zhang ${ }^{3}$, Rong Zhao ${ }^{1}$, Liang Li ${ }^{1}$ and Lanfen Meng ${ }^{1}$
}

\begin{abstract}
Background: Secondary hyperparathyroidism (SHPT) is a severe complication for dialysis patients. Vitamin D receptor activators (VDRAs) are used to treat SHPT, but the comparative efficacy and safety between paricalcitol and other vitamin D receptor activators for management of SHPT in dialysis patients has been unproven.

Methods: We searched PubMed, Embase, and the Cochrane Library for the time period through June 2017 to identify randomized controlled trials that evaluated paricalcitol compared with other VDRAs for treatment of SHPT. The primary outcome was the percentage of patients with target reduction of intact parathyroid hormone (iPTH) from baseline. Secondary outcomes included incidences of hypercalcemia and hyperphosphatemia. The randomeffects model was used to estimate relative risks (RRs) with 95\% confidence intervals (Cls).

Results: Eight studies $(N=759)$ were eligible for final inclusion. Compared with other VDRAs, no significant differences were found in the percentage of patients with target reduction of intact parathyroid hormone (iPTH) from baseline for paricalcitol treatment of SHPT in dialysis patients (RR, $1.01 ; 95 \% \mathrm{Cl}, 0.87-1.18 ; p=0.85)$. There were no differences in the incidence of hypercalcemia (RR, $0.95 ; 95 \% \mathrm{Cl}, 0.74-1.21 ; p=0.65)$ and hyperphosphatemia $(\mathrm{RR}, 0.94 ; 95 \% \mathrm{Cl}$, $0.77-1.16 ; p=0.58$ ).

Conclusions: The presently available evidence is insufficient to draw a conclusion regarding whether paricalcitol therapy has a comparative efficacy and safety over other VDRAs for treating dialysis patients with SHPT. Largesample, well-conducted, high-quality RCTs with patient-level outcomes (i.e., mortality) are urgently needed.
\end{abstract}

Keywords: Paricalcitol, Vitamin D receptor activator, Secondary hyperparathyroidism (SHPT), Hemodialysis, Peritoneal dialysis

\section{Background}

Secondary hyperparathyroidism (SHPT) is one of the most common abnormalities of the chronic kidney diseasemineral and bone disorders (CKD-MBD) syndrome. Abnormalities in serum calcium, phosphorus, intact PTH, and vitamin D deficiency are common in dialysis patients

\footnotetext{
* Correspondence: xieyifeng1983@163.com

'Department of Nephrology, The Third Affiliated Hospital of Guangxi University of Chinese medicine, No.32, Jie-Fang-Bei Road, Cheng-Zhong District, Liuzhou, Guangxi 545001, People's Republic of China

Full list of author information is available at the end of the article
}

with SHPT [1]. Increased levels of serum calcium, phosphorus, and intact PTH had been associated with increased all-cause and cardiovascular mortality [2-6]. However, the DOPPS study indicated that there was a lower mortality risk for calcium, phosphorus, and intact PTH within specific ranges [7]. Based on the epidemiological and clinical evidences, Kidney Disease: Improving Global Outcomes (KDIGO) recommended a target range of serum calcium, phosphorus, and intact $\mathrm{PTH}$ for treating dialysis patients with SHPT [1]. 
To achieve current targets for the key mineral parameters set by KDIGO guidelines, a combination of dietary phosphorus restriction, phosphate binders, vitamin D receptor activators (VDRAs), and adequate dialysis was adopted. Among the VDRAs used for management of SHPT in dialysis patients, paricalcitol is the most potential vitamin $\mathrm{D}$ analog. The observational study by Teng et al. indicated a significant survival advantage of paricalcitol over calcitriol for long-term hemodialysis patients [8]. However, whether or not paricalcitol has a comparative efficacy and safety with other VDRAs for treating SHPT in dialysis patients, based on RCTs, is unknown.

Previous meta-analyses focused mainly on comparisons between paricalcitol and placebo [9-11] in both dialysis patients [12] and patients not requiring dialysis $[9,10,13]$. We performed a meta-analysis making a head-to-head comparison to check therapeutic advantages of paricalcitol over other VDRAs in dialysis patients with SHPT.

\section{Methods}

We conducted a meta-analysis of randomized controlled trials in compliance with the PRISMA (Preferred Reporting Items for Systematic Reviews and Meta-Analyses statement) guidelines [14]. The present meta-analysis had no registered protocol.

\section{Data sources and Searches}

Literature searches for randomized, controlled trials of vitamin D receptor activators in CKD 5D (dialysis) patients with secondary hyperparathyroidism were performed in PubMed, Embase, and the Cochrane Library for the period through January 2016. The Medical Subject Headings $(\mathrm{MeSH})$ terms and corresponding keywords were used for the electronic searches. The search terms used were (MeSH exp. "Kidney Disease," "Kidney Failure," "Chronic Kidney Failure," and the keywords "chronic kidney", "chronic renal", "dialysis" and "hyperparathyroidism"), and (MeSH exp. "Vitamin D" and keywords "vitamin D" and "paricalcitol"). The complete search strategy is outlined in Additional file 1. The cited references of published primary studies and reviews were manually screened to identify relevant trials. To ensure literature saturation, we reran the searches on June 25, 2017. The ClinicalTrials.gov registry (https://clinicaltrials.gov/) was also searched. Trials were identified without language restriction.

\section{Study selection}

Two authors (Yifeng Xie and Peiling Su) independently conducted the search, screened the titles and abstracts, and checked full text for eligibility. Discrepancies between authors were resolved by consensus. Published RCTs meeting the following inclusion criteria were included: (1) population: chronic kidney disease 5D adult patients (hemodialysis or peritoneal dialysis) with secondary hyperparathyroidism; (2) intervention: paricalcitol therapy; (3) comparison: vitamin D analogues such as calcitriol, alfacalcidol, maxacalcitol, et al.; and (4) one or more the following outcomes: percentage of participants with target reduction in intact parathyroid hormone (iPTH) from baseline; incidence of hypercalcemia, hyperphosphatemia, and elevation in calcium phosphorus product; all-cause mortality and end-of-treatment serum phosphorus, calcium, and iPTH levels. Studies that did not meet inclusion criteria (i.e., participants were pediatric patients or comparison was placebo.) were excluded.

\section{Data extraction and Quality assessment}

Data extraction was performed by Yifeng Xie and Peiling $\mathrm{Su}$ using a standardized data extraction sheet (Office Excel $^{\circ}$, Microsoft ${ }^{\circ}$ Corporation) and confirmed independently by another author (Hongsheng Zhang). Three authors double-checked data entry independently. Any disagreements between authors were resolved by discussion and consensus. The collected data included the following: first author, year of publication, country, number of patients, follow-up, age, baseline mineral and bone disorders, laboratory values (serum calcium, phosphorus, and $\mathrm{iPTH}$ ), types of phosphate binders used, dosing schedule, routine of administration, risk of bias data, and outcomes data. Risk of bias data were those that described randomization, double-blinding, and dropouts and withdrawals. Predefined primary outcome was the percentage of patients with target reduction in iPTH from baseline. Secondary outcomes included incidences of hypercalcemia, hyperphosphatemia, and elevation in the calcium-phosphorus product; end-oftreatment serum iPTH, phosphorus, and calcium; and all-cause mortality. For crossover trials, the data from the first period were used [15].

Two authors (Yifeng Xie and Peiling $\mathrm{Su}$ ) independently assessed the risk of bias of the included studies using a validated Jadad 5-point scale [16, 17]. The scale consists of three items describing randomization $(0-2$ points), masking (0-2 points), and dropouts and withdrawals $(0-1$ points) in the report of a randomize controlled trial. The scale ranged from 0 to 5 , with higher scores showing better reporting. The trials were rated high quality when the score was higher than 2 , or low quality when the score was 2 or below, out of a maximum score of 5 .

\section{Statistical analysis}

We summarized effect estimates as relative risks (RRs) for dichotomous outcomes and weighted mean differences for continuous outcomes with 95\% CIs. We assessed heterogeneity of treatment effects across studies with the $\mathrm{I}^{2}$ statistic and $\mathrm{I}^{2}>50 \%$ significant heterogeneity [18]. We pooled effect estimates using a random-effects model, 
taking clinical heterogeneity between studies into account. To examine the influence of various factors on the treatment effects of paricalcitol therapy for dialysis patients with secondary hyperparathyroidism, we performed posthoc subgroup analyses according to baseline serum PTH levels $(\mathrm{PTH}>68.4 \mathrm{pmol} / \mathrm{L}$ versus $\mathrm{PTH}<68.4 \mathrm{pmol} / \mathrm{L}$, with the cut-off value set as 9 times the upper normal limit for the assay), types of dialysis (hemodialysis versus peritoneal dialysis), routine of administration (oral versus intravenous), sample size ( $n>100$ for large sample studies versus $n<100$ for small sample studies), and risk of bias (low quality versus high quality). Publication bias was evaluated visually by funnel plot and quantitatively by Egger's test and Begg's test $[19,20]$. We performed all statistical analyses using RevMan 5.3 (Nordic Cochrane Centre). $P<.05$ was considered statistically significant.

\section{Results}

\section{Trial selection}

The PRISMA statement flowchart shows the process of study identification, screening, selection, and reasons for exclusion, as shown in Fig. 1. The combined search identified a total of 640 records, 614 of which were excluded after removing duplicates and screening the titles and abstracts. Full-text assessment of 26 potentially eligible articles identified 8 studies. Finally, 8 RCTs [21-28] were included in the meta-analysis.

\section{Trials characteristics}

Characteristics of patients and interventions of the included trials are summarized in Table 1 . The sample size ranged from 18 to 263, with a total of 759 patients. Only two trials [21, 27] had more than 100 participants. Of the included trials, seven compared paricalcitol therapy with non-selective vitamin $\mathrm{D}$ receptor activators, including calcitriol and alfacalcidol, and the remaining one [21] compared paricalcitol therapy with selective vitamin D receptor activator (maxacalcitol).

Five trials $[21-24,27]$ reported the primary outcome, which was the percentage of patients with target reduction in intact parathyroid hormone (iPTH) from baseline. Of the five trials reporting the primary outcome, two trials $[23,24]$ used a $>30 \%$ reduction as target reduction, whereas the remaining three trials [21, 22, 27] used $a>50 \%$ reduction. All included trials used different cut-off values to define hypercalcemia, ranging from $2.63 \mathrm{mmol} / \mathrm{L}(10.5 \mathrm{mg} / \mathrm{dL})$ to $2.90 \mathrm{mmol} / \mathrm{L}(11.5 \mathrm{mg} / \mathrm{dL})$. Five trials [21-24, 27] reported incidence of hypercalcemia, one [24] of them using serum ionized calcium and the others serum total calcium. Only one trial [24] presented all-cause mortality data and others did not report patientlevel outcomes (i.e., all-cause mortality, cardiovascular mortality, and fractures). One trial [28] did not present any outcomes, either primary or secondary. All RCTs had a short duration of follow-up, lasting from 5 to 32 weeks.

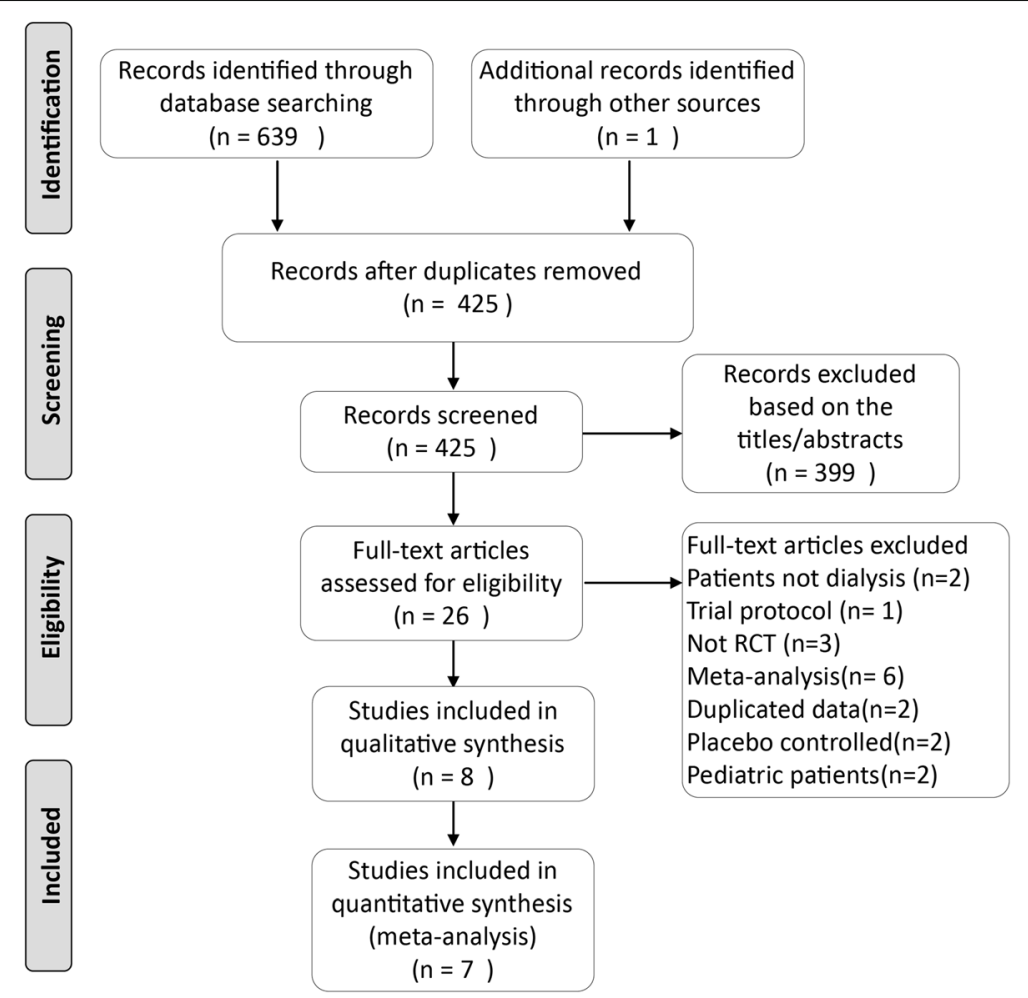

Fig. 1 PRISMA flow diagram for study selection 


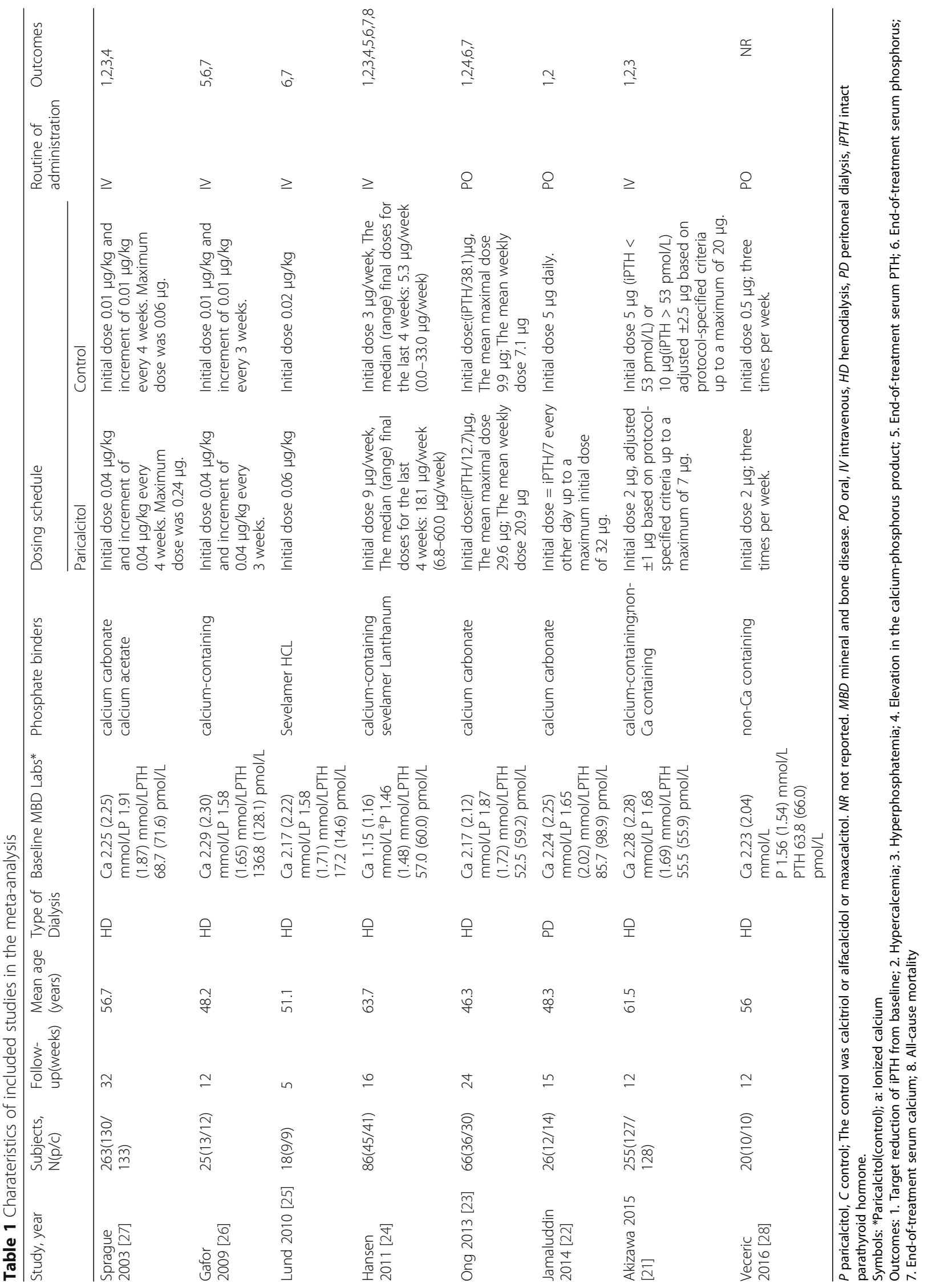




\section{Risk of bias assessment}

The details of risk of bias are listed in Table 2. Overall, four trials $[22,23,26,28]$ were categorized as low methodological quality and four $[21,24,25,27]$ as high methodological quality. Only one trial [24] described appropriate allocation concealment. Three trials [21, 25, 27] reported double-blinding, and all trials except one [28] reported drop-outs and withdrawals.

\section{Paricalcitol treatment versus vitamin D receptor activator treatment \\ Primary outcome}

Five trials [21-24, 27] with a total of 696 patients were included for the outcome of the percentage of patients with target reduction in iPTH from baseline. Compared to either non-selective vitamin $\mathrm{D}$ receptor activators (calcitriol and alfacalcidol) or selective vitamin $\mathrm{D}$ receptor activator (maxacalcitol), paricalcitol had similar efficacy in suppressing the iPTH of dialysis patients with SHPT (Fig. 2.). The RR was 1.01 (95\% CI: 0.87-1.18; $p=0.85$ ). The statistic $\mathrm{I}^{2}$ was $31 \%$, indicating low heterogeneity.

There was no significant difference in suppressing iPTH with paricalcitol in comparison to other VDRAs for all subgroup analyses. Details of subgroup analyses were presented in Table 3.

\section{Secondary outcomes}

There was no significant difference in the risk of hypercalcemia, hyperphosphatemia, and elevation in the calciumphosphorus product with paricalcitol in comparison to other VDRAs, as shown in Fig. 3. The pooled RRs with 95\% CI for incidence of hypercalcemia, hyperphosphatemia, and elevation in the calcium-phosphorus product were $0.95(0.74-$ $1.21 ; p=0.65)$, 0.94 (0.77-1.16; $p=0.58), 1.08$ (0.81-1.44; $p=0.60)$, respectively. The statistic $\mathrm{I}^{2}$ was $0 \%$ for all three outcomes.

There was no significant difference in end-of-treatment serum calcium and phosphorus with paricalcitol in comparison to other VDRAs, as shown in Fig. 4. The pooled mean differences (MDs) with $95 \% \mathrm{CI}$ were $0(-0.06-0.05$; $p=0.95)$ and $-0.08(-0.19-0.03 ; p=0.15)$, respectively. The statistics $\mathrm{I}^{2}$ were $24 \%$ and $0 \%$, respectively.

\section{Discussion}

This meta-analysis demonstrates that there was no significant difference in effectiveness and safety of paricalcitol therapy in comparison to other VDRAs based on the biochemical end points when treating adult dialysis patients with secondary hyperparathyroidism. Comparisons based on patient-centered outcomes are not possible presently because of the lack of RCTs providing data on patient-level outcomes, such as mortality, cardiovascular death, fracture, and quality of life.

KDIGO's recommendations on dialysis patients with SHPT are to lower elevated phosphorus levels toward the normal range while maintaining intact PTH levels in the range of $\sim 2-9$ times the upper normal limit for the assay and maintaining serum calcium in the normal range [1]. To reach the treatment target, limited dietary intake of phosphorus, phosphate binder, Vitamin D compounds, and adequate dialysis are adopted. A metaanalysis of 14 observational studies demonstrated that vitamin $\mathrm{D}$ compound therapies reduced mortality in CKD patients, particularly in those suffering from secondary hyperparathyroidism [29]. A study by Teng et al. showed that paricalcitol had a survival advantage over calcitriol in patients undergoing long-term hemodialysis [8]. However, all the included trials in this meta-analysis did

Table 2 Assessing risk of bias of the included studies by validated Jadad 5-point scale

\begin{tabular}{|c|c|c|c|c|c|c|c|c|}
\hline Author & $\begin{array}{l}\text { Publication } \\
\text { year }\end{array}$ & Country & $\begin{array}{l}\text { Sample } \\
\text { size }(n)\end{array}$ & Study Design & $\begin{array}{l}\text { Randomization } \\
\text { (0-2 points) }\end{array}$ & $\begin{array}{l}\text { Double-blind } \\
\text { (0-2 points) }\end{array}$ & $\begin{array}{l}\text { Drop-outs and withdrawals } \\
\text { (0-1 points) }\end{array}$ & $\begin{array}{l}\text { Jadad } \\
\text { score }\end{array}$ \\
\hline Sprague [27] & 2003 & USA & 263 & $\begin{array}{l}\text { multicenter, double-blind, } \\
\text { parallel }\end{array}$ & 1 & 2 & 1 & 4 \\
\hline Gafor [26] & 2009 & Malaysia & 25 & $\begin{array}{l}\text { single-center, open-labelled, } \\
\text { parallel }\end{array}$ & 1 & 0 & 1 & 2 \\
\hline Lund [25] & 2010 & USA & 18 & $\begin{array}{l}\text { single-center, double-blind, } \\
\text { crossover }\end{array}$ & 1 & 2 & 1 & 4 \\
\hline Hansen [24] & 2011 & Denmark & 86 & $\begin{array}{l}\text { multicenter, open-labelled, } \\
\text { crossover }\end{array}$ & 2 & 0 & 1 & 3 \\
\hline Ong [23] & 2013 & Malaysia & 66 & $\begin{array}{l}\text { multicentre, open-labelled, } \\
\text { parallel }\end{array}$ & 1 & 0 & 1 & 2 \\
\hline Jamaluddin [22] & 2014 & Malaysia & 26 & $\begin{array}{l}\text { single-center, open-labelled, } \\
\text { parallel }\end{array}$ & 1 & 0 & 1 & 2 \\
\hline Akizawa [21] & 2015 & Japan & 255 & $\begin{array}{l}\text { multicenter, double-blind, } \\
\text { parallel }\end{array}$ & 1 & 2 & 1 & 4 \\
\hline Veceric [28] & 2016 & Slovenia & 20 & $\begin{array}{l}\text { single-center, open-labelled, } \\
\text { parallel }\end{array}$ & 1 & 0 & 0 & 1 \\
\hline
\end{tabular}




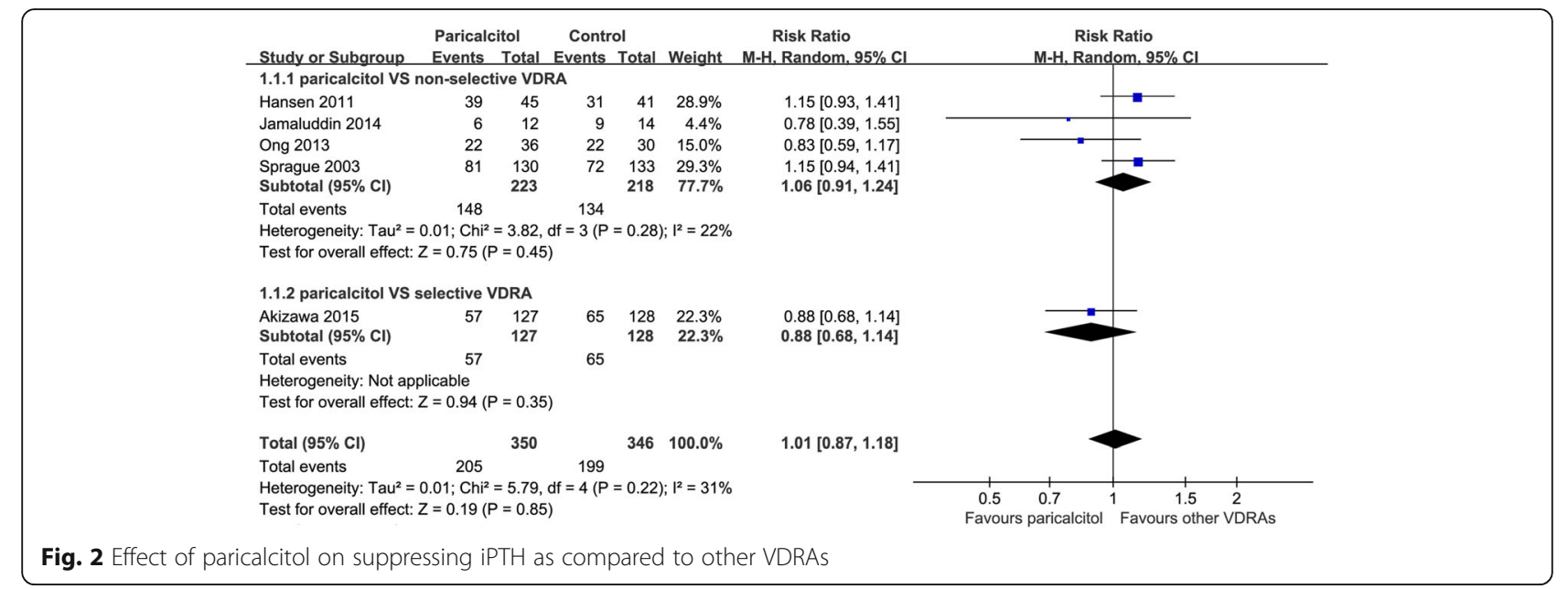

not report patient-level outcomes. Comparisons based on the biochemical end points did not demonstrate an advantage of paricalcitol therapy over other VDRAs therapies. Several factors may affect both direction and size of the effect estimates and account for a risk of bias across the included studies. First, there was a diverse spectrum of iPTH at the baseline, ranging from $14.6 \mathrm{pmol} / \mathrm{L}$ to $136.8 \mathrm{pmol} / \mathrm{L}$. Second, the majority of the included studies had a small sample size $(n<100)$ with inadequate power. Third, there were two target-reduction values of $\mathrm{iPTH}$ $(>30 \%$ and $>50 \%$ ) for the definition of primary outcome. Also, there were different cut-off values for the definition of hypercalcemia. Fourth, different types of phosphate binders were used in the included trials. A meta-analysis showed that non-calcium-containing phosphate binders had an advantage of a decrease in hypercalcemia in dialysis patients over the calcium-containing phosphate binders [30]. Fifth, dose ratios of $4: 1$ and 3:1, or an initial dose, depending on iPTH level, were used. Thus, the potential dose-response might affect the effect size [31]. Sixth, durations of follow-up were too short for the included studies. Seventh, fibroblast growth factor 23 (FGF 23) plays an important role in the mineral and bone disorders of CKD patients [32-35]. However, the included studies of this meta-analysis had no information on the serum FGF23 levels of patients enrolled in the studies, except that one study provided incomplete data of FGF23 [36]. Any significant within-group or between-group differences of FGF23 may affect the treatment effects of the included trials.

Table 3 Subgroup analyses of paricalcitol compared with other VDRAs for target reduction of iPTH from baseline

\begin{tabular}{|c|c|c|c|c|c|c|}
\hline Subgroup & No.patients & No.trials & Relative Risk(95\% Cl) & $P$ Value & $I^{2}(\%)$ & Test of Interaction, P \\
\hline Total & 696 & 5 & $1.01(0.87,1.18)$ & 0.85 & 31 & Not applicable \\
\hline \multicolumn{7}{|l|}{ Baseline iPTH level } \\
\hline$<68.4 \mathrm{pmol} / \mathrm{L}$ & 407 & 3 & $0.97(0.78,1.20)$ & 0.77 & 51 & \multirow[t]{2}{*}{0.49} \\
\hline$>68.4 \mathrm{pmol} / \mathrm{L}$ & 289 & 2 & $1.09(0.84,1.42)$ & 0.51 & 13 & \\
\hline \multicolumn{7}{|l|}{ Types of dialysis } \\
\hline Hemodialysis & 670 & 4 & $1.03(0.87,1.20)$ & 0.76 & 41 & \multirow[t]{2}{*}{0.44} \\
\hline Peritoneal dialysis & 26 & 1 & $0.78(0.39,1.55)$ & 0.47 & 31 & \\
\hline \multicolumn{7}{|c|}{ Routine of administration } \\
\hline Oral & 92 & 2 & $0.82(0.61,1.11)$ & 0.21 & 0 & \multirow[t]{2}{*}{0.14} \\
\hline Intravenous & 604 & 3 & $1.07(0.91,1.26)$ & 0.42 & 38 & \\
\hline \multicolumn{7}{|l|}{ Sample size } \\
\hline Small, $n<100$ & 178 & 3 & $0.98(0.75,1.28)$ & 0.87 & 42 & \multirow[t]{2}{*}{0.82} \\
\hline Large, $n>100$ & 518 & 2 & $1.02(0.79,1.32)$ & 0.88 & 60 & \\
\hline \multicolumn{7}{|l|}{ Risk of bias } \\
\hline Low quality & 92 & 2 & $0.82(0.61,1.11)$ & 0.21 & 0 & \multirow[t]{2}{*}{0.14} \\
\hline High quality & 604 & 3 & $1.07(0.91,1.26)$ & 0.42 & 38 & \\
\hline
\end{tabular}




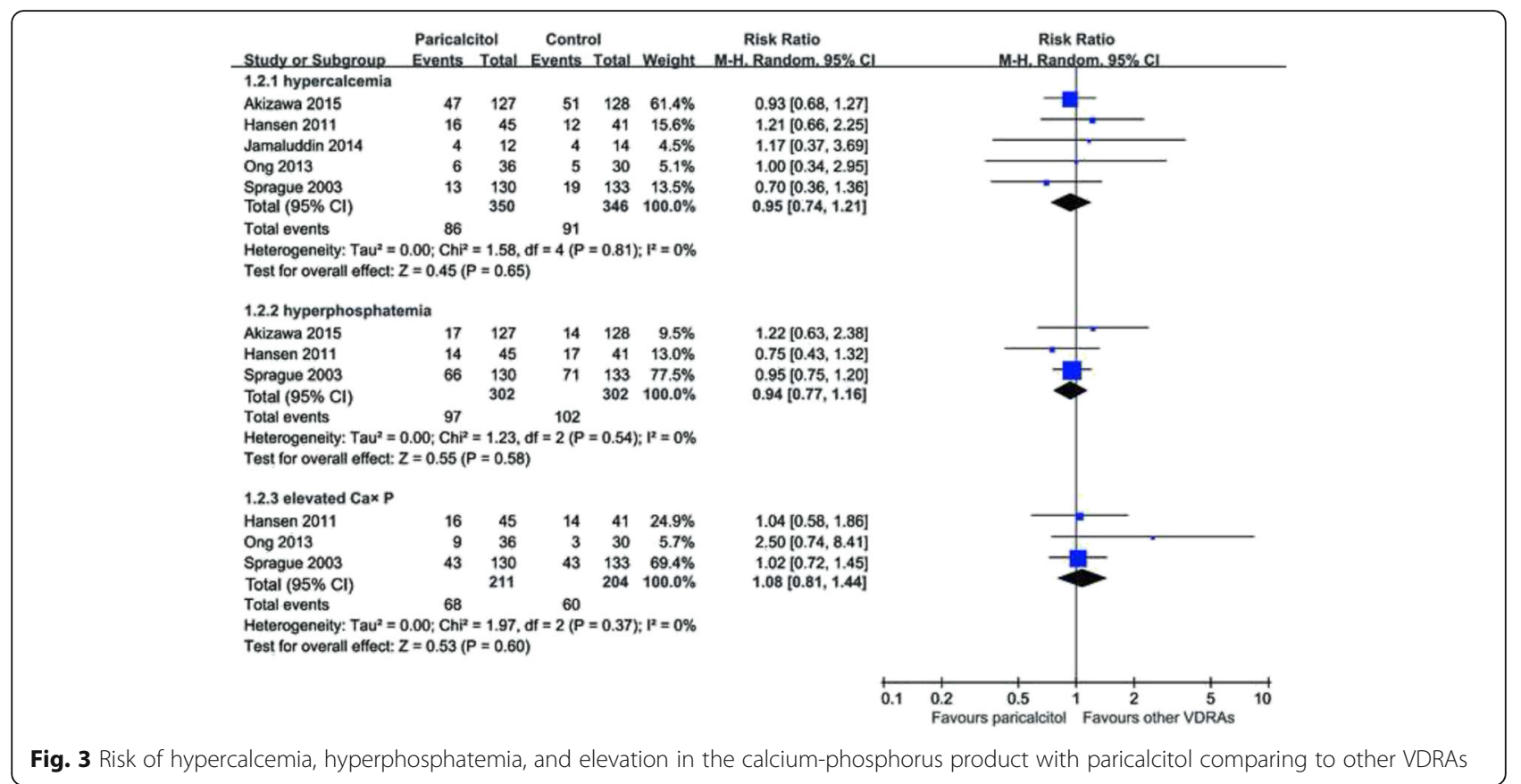

The negative result of our meta-analysis is consistent with previous meta-analyses [12, 37, 38]; however, this meta-analysis reveals several differences. First, the population is limited to CKD adult dialysis patients with SHPT. Patients not on dialysis were excluded because of significant differences of the association between serum phosphorus/calcium/iPTH and mortality in these two types of patients $[1,39,40]$. Second, active VDRA treatments were chosen as controls in this meta-analysis; thus, a direct comparison between paricalcitol and other VDRAs is made to check the superiority. Third, compared with recently published meta-analyses [37], this meta-analysis adds a comparison between selective vitamin D analogues (paricalcitol versus maxacalcitol).

This meta-analysis has the following limitations: First, the number of included studies is small and the studies had small sample sizes and short follow-up lengths. Second, the number of included trials is too small to evaluate publication bias of our meta-analysis, either visually by funnel plot or quantitatively by Egger's test [20] and Begg's test [19]. There may be potential publication bias in this meta-analysis. Third, comparisons between paricalcitol and other VDRAs are based on biochemical end points. Patient-level outcomes are not available in the included studies. Fourth, since the control included both non-selectvie VDRAs and selective VDRAs, this could introduce some heterogeneity for the summarized effect.

\section{Conclusions}

The evidence that is presently available is insufficient to draw a conclusion regarding whether paricalcitol therapy has a comparative efficacy and safety over other VDRAs

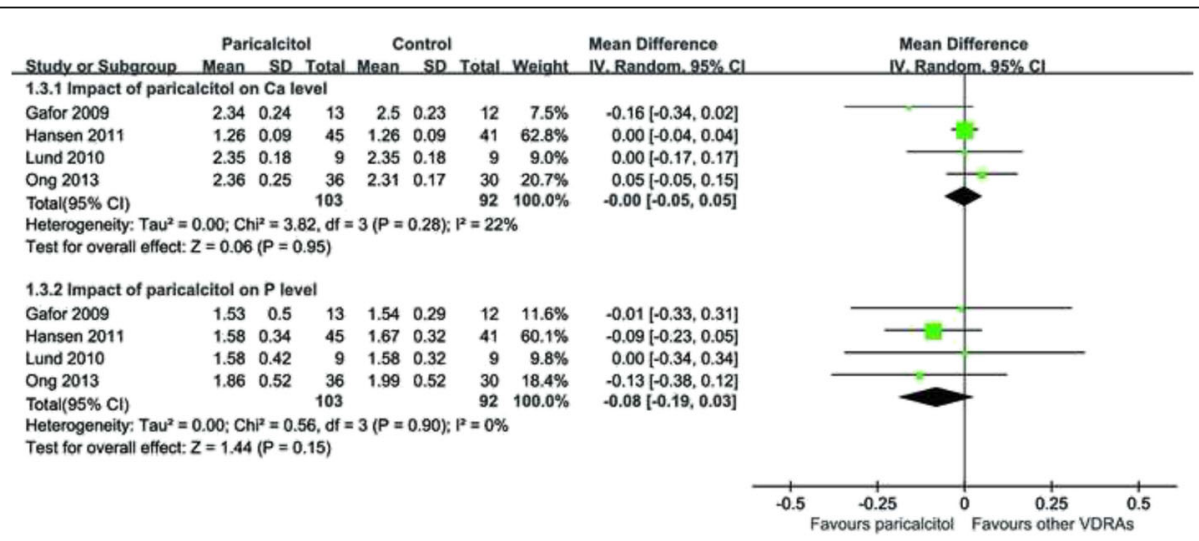

Fig. 4 Effect of paricalcitol on end-of-treatment serum calcium and phosphorus as compared to other VDRAs 
for treating dialysis patients with SHPT. Large-sample, well-conducted, high-quality RCTs with patient-level outcomes (i.e., mortality) are urgently needed.

\section{Additional file}

Additional file 1: Search Strategy. (DOCX $18 \mathrm{~kb})$

\section{Abbreviations}

$\mathrm{Cl}$ : Confidence interval; CKD: Chronic kidney disease; CKD-MBD: Chronic kidney disease-mineral and bone disorder; iPTH: Intact parathyroid hormone; KDIGO: Kidney Disease: Improving Global Outcomes; MD: Mean difference; MeSH: Medical Subject Headings; PRISMA: Preferred Reporting Items for Systematic Reviews and Meta-Analyses; RCT: Randomized controlled trial; RR: Relative risk; SHPT: Secondary hyperparathyroidism; VDRA: Vitamin D receptor activator

\section{Acknowledgements}

The authors thank Shifu Tang for his assistance with statistic aspects of the review.

\section{Funding}

This study is supported by the Guangxi University of Chinese Medicine Natural Science Research Foundation (2015MS025).

\section{Availability of data and materials}

All datasets analyzed in this meta-analysis are referenced in the manuscript, its Additional file 1.

\section{Authors' contributions}

XYF contributed to concept and design of the study, acquisition, analysis and interpretation of data, drafting and revising the article, and final approval of the manuscript. SPL, SYF and ZHS contributed to acquisition, analysis and interpretation of data, drafting the article, and final approval of the manuscript. ZR, LL and MLF contributed to concept and design of the study, analysis and interpretation of data, revising the article, final approval of the manuscript to be published.

\section{Ethics approval and consent to participate}

Not applicable.

\section{Consent for publication}

Not applicable.

\section{Competing interests}

The authors declare that they have no competing interests.

\section{Publisher's Note}

Springer Nature remains neutral with regard to jurisdictional claims in published maps and institutional affiliations.

\section{Author details}

'Department of Nephrology, The Third Affiliated Hospital of Guangxi University of Chinese medicine, No.32, Jie-Fang-Bei Road, Cheng-Zhong District, Liuzhou, Guangxi 545001, People's Republic of China. ²Department of Clinical Laboratory, The Third Affiliated Hospital of Guangxi University of Chinese medicine, Liuzhou, Guangxi, People's Republic of China. ${ }^{3}$ Department of Orthopaedics, The Third Affiliated Hospital of Guangxi University of Chinese medicine, Liuzhou, Guangxi, People's Republic of China.

Received: 4 May 2016 Accepted: 18 August 2017

Published online: 25 August 2017

\section{References}

1. Kidney Disease. Improving Global Outcomes (KDIGO) CKD-MBD Work Group. KDIGO clinical practice guideline for the diagnosis, evaluation, prevention, and treatment of Chronic Kidney Disease-Mineral and Bone Disorder (CKD-MBD). Kidney Int Suppl. 2009(113):S1-130.
2. Block GA, Klassen PS, Lazarus JM, Ofsthun N, Lowrie EG, Chertow GM. Mineral metabolism, mortality, and morbidity in maintenance hemodialysis. J Am Soc Nephrol. 2004;15(8):2208-18.

3. Melamed ML, Eustace JA, Plantinga $L$, et al. Changes in serum calcium, phosphate, and PTH and the risk of death in incident dialysis patients: a longitudinal study. Kidney Int. 2006;70(2):351-7.

4. Young EW, Albert JM, Satayathum S, et al. Predictors and consequences of altered mineral metabolism: the Dialysis Outcomes and Practice Patterns Study. Kidney Int. 2005;67(3):1179-87.

5. Kalantar-Zadeh K, Kuwae N, Regidor DL, et al. Survival predictability of timevarying indicators of bone disease in maintenance hemodialysis patients. Kidney Int. 2006;70(4):771-80.

6. Ganesh SK, Stack AG, Levin NW, Hulbert-Shearon T, Port FK. Association of elevated serum $\mathrm{PO}(4), \mathrm{Ca} \times \mathrm{PO}(4)$ product, and parathyroid hormone with cardiac mortality risk in chronic hemodialysis patients. J Am Soc Nephrol. 2001;12(10):2131-8.

7. Tentori F, Blayney MJ, Albert JM, et al. Mortality risk for dialysis patients with different levels of serum calcium, phosphorus, and PTH: The Dialysis Outcomes and Practice Patterns Study (DOPPS). Am J Kidney Dis. 2008;52(3):519-30.

8. Teng M, Wolf M, Lowrie E, Ofsthun N, Lazarus JM, Thadhani R. Survival of patients undergoing hemodialysis with paricalcitol or calcitriol therapy. $\mathrm{N}$ Engl J Med. 2003;349(5):446-56.

9. Cheng J, Zhang W, Zhang X, Li X, Chen J. Efficacy and Safety of Paricalcitol Therapy for Chronic Kidney Disease: A Meta-Analysis. Clin J Am Soc Nephrol. 2012;7(3):391-400

10. Han T, Rong G, Quan D, et al. Meta-analysis: the efficacy and safety of paricalcitol for the treatment of secondary hyperparathyroidism and proteinuria in chronic kidney disease. Biomed Res Int. 2013;2013:-320560.

11. Li X-H, Feng L, Yang Z-H, Liao Y-H. Effect of active vitamin D on cardiovascular outcomes in predialysis chronic kidney diseases: A systematic review and meta-analysis. Nephrology. 2015;20(10):706-14.

12. Palmer SC, McGregor DO, Craig JC, Elder G, Macaskill P, Strippoli GFM. Vitamin D compounds for people with chronic kidney disease requiring dialysis. Cochrane Database Syst Rev. 2009;4

13. Palmer SC, McGregor DO, Craig JC, Elder G, Macaskill P, Strippoli GFM. Vitamin D compounds for people with chronic kidney disease not requiring dialysis. Cochrane Database Syst Rev. 2009;4

14. Moher D, Liberati A, Tetzlaff J, Altman DG, Grp P. Preferred reporting items for systematic reviews and meta-analyses: The PRISMA statement. Int J Surg. 2010;8(5):336-41.

15. Stedman MR, Curtin F, Elbourne DR, Kesselheim AS, Brookhart MA. Metaanalyses involving cross-over trials: methodological issues. Int J Epidemiol. 2011:40(6):1732-4.

16. Moher D, Pham B, Jones A, et al. Does quality of reports of randomised trials affect estimates of intervention efficacy reported in meta-analyses? Lancet. 1998;352(9128):609-13.

17. Jadad AR, Moore RA, Carroll D, et al. Assessing the quality of reports of randomized clinical trials: is blinding necessary? Control Clin Trials. 1996:17(1):1-12

18. Higgins JP, Thompson SG, Deeks JJ, Altman DG. Measuring inconsistency in meta-analyses. BMJ. 2003;327(7414):557-60.

19. Begg CB, Mazumdar M. Operating characteristics of a rank correlation test for publication bias. Biometrics. 1994;50(4):1088-101.

20. Egger M, Davey Smith G, Schneider M, Minder C. Bias in meta-analysis detected by a simple, graphical test. BMJ. 1997:315(7109):629-34.

21. Akizawa T, Akiba T, Hirakata $\mathrm{H}$, et al. Comparison of paricalcitol with maxacalcitol injection in Japanese hemodialysis patients with secondary hyperparathyroidism. Ther Apher Dial. 2015;19(3):225-34.

22. Jamaluddin EJ, Gafor AH, Yean LC, et al. Oral paricalcitol versus oral calcitriol in continuous ambulatory peritoneal dialysis patients with secondary hyperparathyroidism. Clin Exp Nephrol. 2014;18(3):507-14.

23. Ong LM, Narayanan P, Goh HK, et al. Randomized controlled trial to compare the efficacy and safety of oral paricalcitol with oral calcitriol in dialysis patients with secondary hyperparathyroidism. Nephrology. 2013;18(3):194-200.

24. Hansen D, Rasmussen $\mathrm{K}$, Danielsen $\mathrm{H}$, et al. No difference between alfacalcidol and paricalcitol in the treatment of secondary hyperparathyroidism in hemodialysis patients: a randomized crossover trial. Kidney Int. 2011:80(8):841-50.

25. Lund RJ, Andress DL, Amdahl M, Williams LA, Heaney RP. Differential Effects of Paricalcitol and Calcitriol on Intestinal Calcium Absorption in Hemodialysis Patients. Am J Nephrol. 2010;31(2):165-70. 
26. Abdul Gafor AH, Saidin R, Loo CY, et al. Intravenous calcitriol versus paricalcitol in haemodialysis patients with severe secondary hyperparathyroidism. Nephrology. 2009;14(5):488-92.

27. Sprague SM, Llach F, Amdahl M, Taccetta C, Batlle D. Paricalcitol versus calcitriol in the treatment of secondary hyperparathyroidism. Kidney Int. 2003;63(4):1483-90.

28. Veceric-Haler Z, Romozi K, Antonic M, et al. Comparison of the Pharmacological Effects of Paricalcitol Versus Calcitriol on Secondary Hyperparathyroidism in the Dialysis Population. Ther Apher Dial. 2016;20(3):261-6.

29. Duranton F, Rodriguez-Ortiz ME, Duny Y, Rodriguez M, Daures JP, Argiles A. Vitamin D treatment and mortality in chronic kidney disease: a systematic review and meta-analysis. Am J Nephrol. 2013;37(3):239-48.

30. Navaneethan SD, Palmer SC, Craig JC, Elder GJ, Strippoli GF. Benefits and harms of phosphate binders in CKD: a systematic review of randomized controlled trials. Am J Kidney Dis. 2009:54(4):619-37.

31. Miller JE, Molnar MZ, Kovesdy CP, et al. Administered paricalcitol dose and survival in hemodialysis patients: a marginal structural model analysis. Pharmacoepidemiol Drug Saf. 2012;21(11):1232-9.

32. Silver J, Naveh-Many T. FGF-23 and secondary hyperparathyroidism in chronic kidney disease. Nat Rev Nephrol. 2013;9(11):641-9.

33. Hu MC, Shiizaki K, Kuro-o M, Moe OW. Fibroblast growth factor 23 and Klotho: physiology and pathophysiology of an endocrine network of mineral metabolism. Annu Rev Physiol. 2013;75:503-33.

34. Gutierrez O, Isakova T, Rhee $\mathrm{E}$, et al. Fibroblast growth factor-23 mitigates hyperphosphatemia but accentuates calcitriol deficiency in chronic kidney disease. J Am Soc Nephrol. 2005;16(7):2205-15.

35. Isakova T, Wahl P, Vargas GS, et al. Fibroblast growth factor 23 is elevated before parathyroid hormone and phosphate in chronic kidney disease. Kidney Int. 2011;79(12):1370-8.

36. Hansen D, Rasmussen K, Pedersen SM, Rasmussen LM, Brandi L. Changes in fibroblast growth factor 23 during treatment of secondary hyperparathyroidism with alfacalcidol or paricalcitol. Nephrol Dial Transplant. 2012;27(6):2263-9.

37. Cai P, Tang X, Qin W, Ji L, Li Z. Comparison between paricalcitol and active non-selective vitamin $\mathrm{D}$ receptor activator for secondary hyperparathyroidism in chronic kidney disease: a systematic review and meta-analysis of randomized controlled trials. Int Urol Nephrol. 2016;

38. Palmer SC, McGregor DO, Macaskill P, Craig JC, Elder GJ, Strippoli GFM. Meta-analysis: Vitamin D compounds in chronic kidney disease. Ann Intern Med. 2007;147(12):840-53.

39. Uhlig K. What should a guideline panel do when evidence is inconclusive? The case of treatments for CKD-mineral and bone disorder (CKD-MBD). Am J Kidney Dis. 2011;58(6):872-5.

40. Palmer SC, Hayen A, Macaskill P, et al. Serum levels of phosphorus, parathyroid hormone, and calcium and risks of death and cardiovascular disease in individuals with chronic kidney disease: a systematic review and meta-analysis. JAMA. 2011;305(11):1119-27.

\section{Submit your next manuscript to BioMed Central and we will help you at every step:}

- We accept pre-submission inquiries

- Our selector tool helps you to find the most relevant journal

- We provide round the clock customer support

- Convenient online submission

- Thorough peer review

- Inclusion in PubMed and all major indexing services

- Maximum visibility for your research

Submit your manuscript at www.biomedcentral.com/submit 